\title{
The validity of predicting prognosis by the number of lymph node metastases in node-positive colon cancer*
}

\author{
Kiichi Sugimoto, Masaya Kawai, Kazuhiro Takehara, Yoshihiko Tashiro, Shinya Munakata, \\ Kiichi Nagayasu, Koichiro Niwa, Shun Ishiyama, Hiromitsu Komiyama, Makoto Takahashi, \\ Yutaka Kojima, Michitoshi Goto, Yuichi Tomiki, Kazuhiro Sakamoto
}

Department of Coloproctological Surgery, Faculty of Medicine, Juntendo University, Tokyo, Japan

Email: ksugimo@juntendo.ac.jp

Received 22 May 2013; revised 22 June 2013; accepted 15 July 2013

Copyright (C) 2013 Kiichi Sugimoto et al. This is an open access article distributed under the Creative Commons Attribution License, which permits unrestricted use, distribution, and reproduction in any medium, provided the original work is properly cited.

\begin{abstract}
Background: We examined the possibility of predicting prognosis by the number of lymph node metastases. Methods: Two hundred and forty-nine patients with lymph node metastases who underwent curative surgery for colon cancer were enrolled in this study. We calculated cancer-specific survival according to the number of lymph node metastases. Results: There was a tendency toward better rates of cancer-specific survivals among the patients with 1 LNM, compared with those with 2 LNM $(p=0.07)$. When comparing cancer-specific survival between the patients with 1, 2 - 3 and 4 or more lymph node metastases, cancerspecific survival was well stratified $(p<0.0001)$. With regard to stage classification, in the Japanese classification, there was a significant difference in cancerspecific survival between Stages IIIa and IIIb $(p<$ 0.0001 ). On the other hand, in the TNM classification, cancer-specific survivals in Stages IIIA, IIIB and IIIC were stratified into three groups with significant differences (IIIA vs. IIIB; $p=0.007$, IIIB vs. IIIC; $p<$ 0.0001). Conclusion: It appeared to be valid to stratify cancer-specific survival into three groups, i.e., the patients with 1, 2 and 3 and 4 or more lymph node metastases. This study was in favor of the TNM classification in which $\mathbf{N}$ category is classified by the number of lymph node metastases.
\end{abstract}

Keywords: Colon Cancer; Lymph Node Metastasis; Stage Classification; TNM Classification; Prognostic Factors

\section{INTRODUCTION}

Colorectal cancer is a major cause of cancer death in the

${ }^{*}$ Conflict of interest statement: Authors have no conflict of interest.
United States and Japan, and its incidence is rapidly increasing in Japan [1,2]. Several prognostic factors have been evaluated in colorectal cancer [3-7]. Nodal involvement is accepted as one of the important prognostic factors in colorectal cancer [8-10] and postoperative adjuvant chemotherapy is recommended for node-positive colorectal cancer $[11,12]$. In the United States the number of lymph node metastases (LNM) is regarded as an important prognostic factor in node-positive colorectal cancer and stage classification by the number of LNM has been adopted in the TNM classification of malignant tumors, 7th Edition [13]. In Japan, stage classification by the distribution of LNM has been modified to that by the number of LNM in order to also integrate with the TNM classification in the Japanese classification of colorectal carcinoma 2nd English Edition [14]. However, there have been few reports regarding the validity of predicting prognosis by the number of LNM in node-positive colon cancer in Japan. We retrospectively examined the possibility of predicting prognosis by the number of LNM and considered the validity of stage classification in TNM classification and Japanese classification.

\section{METHODS}

\subsection{Patient Selection}

Two hundred and forty-nine patients with LNM who underwent curative surgery for colon cancer at our department between January 1992 and December 2004 were enrolled in this study. We retrospectively reviewed the database and medical records. All patients were followed for 5 years after the operation. Cases with multiple primary cancer, preoperative adjuvant therapy and 11 or fewer dissected lymph nodes, and cases that died because of non cancer-related causes were excluded from this study. The median observation period 
was 8.6 years (range: $0.2-14.6$ yeras).

\subsection{Clinicopathological Analysis}

We first calculated cancer-specific survival according to the number of LNM in order to examine whether or not stratification of the prognosis by the number of LNM is appropriate. Secondly, clinicopathological factors, such as age, gender (male/female), location (proximal/distal), invasion depth (TNM classification: T1-T3/T4), differentiation (well differentiated adenocarcinoma/others), lymphatic invasion (none-mild/moderate-severe), venous invasion (none-mild/moderate-severe), preoperative serum CEA, the number of dissected lymph nodes, the number of LNM and survival data were analyzed to determine prognostic factors related to cancer-specific survival. Finally, we considered the differences between the TNM classification and the Japanese classification.

\subsection{Pathological Examination}

All specimens were examined in the following manner: After resection of the primary tumor, the excised specimen was opened on the antimesenteric side by the surgeon. The surgeon identified the lymph nodes, isolated them, and recorded both their number and distribution. After formalin fixation, the specimens and lymph nodes were examined by the pathologist.

\subsection{Follow-Up Program}

All patients were followed for 5 years after the operation. During the first 3 years, patients were followed every 3 months with clinical assessment and measurement of serum carcinoembryonic antigen, and every 3 - 6 months with chest X-ray and abdominal ultrasonography or computed tomography. For the remaining 2 years, all tests were performed every 6 months. Colonoscopy was performed 1 year after the operation and every 2 years for the next 4 years.

\subsection{Statistical Analysis}

Discrete variables were compared using Fisher's exact probability test and continuous variables were compared using the Mann-Whitney U-test. Clinicopathological factors, for which there was a significant difference in the univariate analysis, were used as covariables for the multivariate analysis. For the multivariate analysis, the Cox proportional-hazard model was used with the Hazard ratio as a measure of association by applying a stepwise procedure. The survival rate was calculated using the Kaplan-Meier method and univariate analyses were performed using the log-rank test. Data were statistically analyzed using JMP 9.0.2 software (SAS Institute Inc., Cary, NC, USA). Differences were considered statisti- cally significant at $\mathrm{p}<0.05$. Values are expressed as median (min. - max.).

\section{RESULTS}

\subsection{The Stratification of Cancer-Specific Survival According to the Number of Lymph Node Metastases}

Cancer-specific survival according to the number of LNM is shown in Figure 1. Cancer-specific survival of the patients with 5 or 7 LNM was better than those with 4 or 6 LNM. With the exception of those cases, cancerspecific survival was worse as the number of LNM increased. When comparing cancer-specific survival according to the number of LNM, there was a tendency toward better rates of cancer-specific survivals among the patients with 1 LNM, compared with those with 2 LNM $(p=0.07)$ (Table 1). There were no significant differences in cancer-specific survival between the patients with 3 or more LNM. Next, we examined whether or not stratification of the cancer-specific survival according to the number of LNM was possible. When dividing the number of LNM into groups (i.e., 2/3 $\leq, 2-3 / 4 \leq, 2-4 / 5 \leq$, etc.), except for the patients with one LNM, among whom cancer-specific survival was better, there were significant differences in cancer-specific survival between groups (i.e., $2-3 / 4 \leq, 2-4 / 5 \leq, 2-5 / 6 \leq)(p=0.007$,

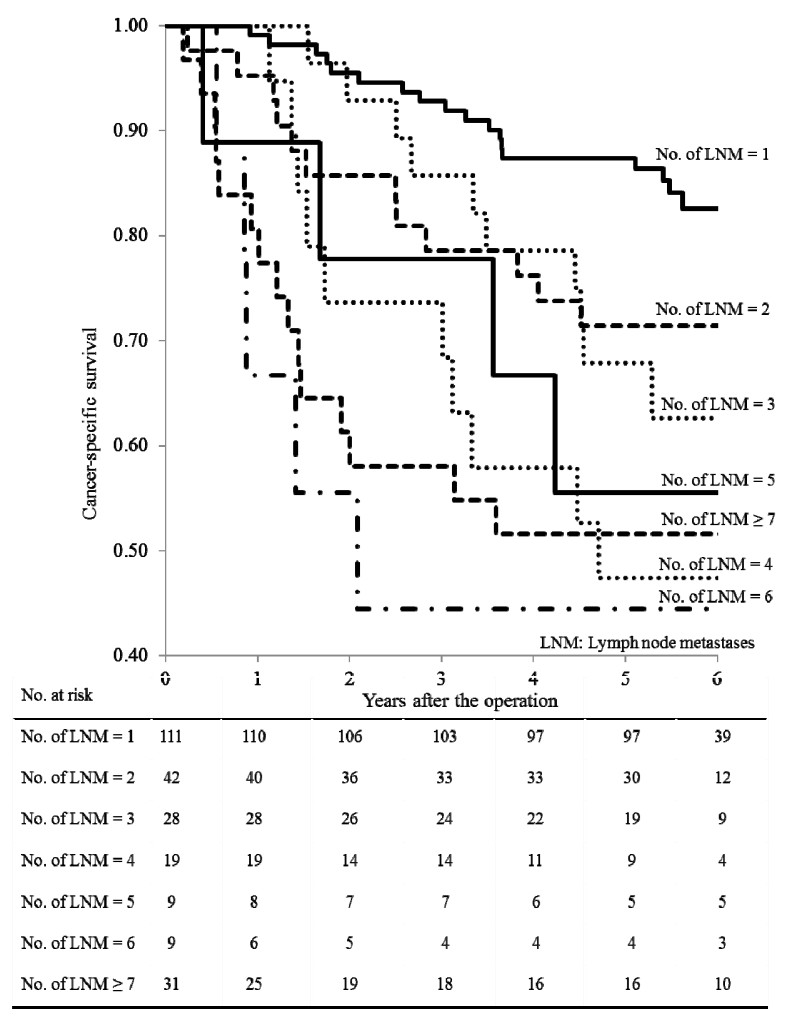

Figure 1. Cancer-specific survival according to number of lymph node metastases. 
$\mathrm{p}=0.03, \mathrm{p}=0.02$, respectively) (Table 2). Among them, the p-value was lowest in comparison of the cancer-specific survival between the patients with $2-3$ and 4 or more LNM. Therefore, when comparing cancer-specific survival between the patients with $1,2-3$ and 4 or more LNM, cancer-specific survival was well stratified $(\mathrm{p}<0.0001)$ (Figure 2).

\subsection{Prognostic Factors for 5-Year Survival}

There were 76 patients $(30.5 \%)$ in the non-survivor group. In univariate analysis of the non-survivor group compared with the 5-year survivor group, there were significantly more patients with invasion depth (T4) (p = $0.0001)$, lymphatic invasion (moderate-severe) $(\mathrm{p}=$ $0.003)$, venous invasion (moderate-severe) $(p=0.0002)$ and the number of LNM $(\mathrm{p}<0.0001)$ (Table 3). With respect to the other clinicopathological factors, there were no significant differences between the two groups. According to the multivariate analysis using these clinicopathological factors, invasion depth (T4) ( $p=0.004$, Odds ratio $=2.43)$, venous invasion (moderate-severe) $(p$ $=0.04$, Odds ratio $=1.98)$ and the number of LNM $(\mathrm{p}=$ 0.0007 , Odds ratio $=1.19$ ) were significant independent

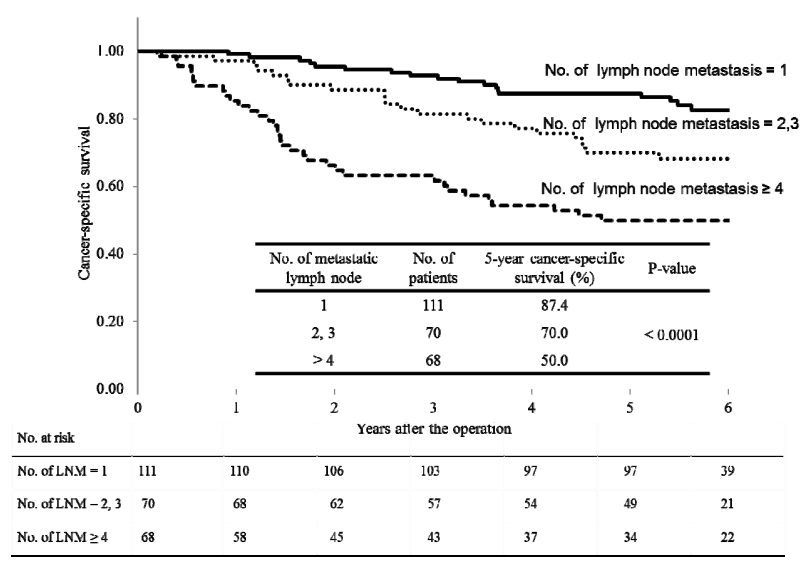

Figure 2. Stratification of the cancer-specific survival according to the number of lymph node metastases.

Table 1. Differences in cancer-specific survival according to number of lymph node metastases.

\begin{tabular}{cccc}
\hline $\begin{array}{c}\text { No. of lymph } \\
\text { node metastases }\end{array}$ & $\begin{array}{c}\text { No. of } \\
\text { patients }\end{array}$ & $\begin{array}{c}\text { 5-year cancer } \\
\text { specific survival (\%) }\end{array}$ & p-value \\
\hline 1 & 111 & 87.4 & ]$_{0.07}$ \\
2 & 42 & 71.4 & ]$_{0.69}$ \\
3 & 28 & 67.9 & ] 0.16 \\
4 & 19 & 47.4 & ]$_{0.70}$ \\
5 & 9 & 55.6 & ]$_{0.50}$ \\
6 & 9 & 44.4 & ] 0.80 \\
$\geq 7$ & 31 & 51.6 & \\
Total & 249 & & \\
\hline
\end{tabular}

Table 2. Stratification of the cancer-specific survival according to the number of lymph node metastases except for the patients with one lymph node metastasis.

\begin{tabular}{cccc}
\hline $\begin{array}{c}\text { No. of lymph node } \\
\text { metastases }\end{array}$ & $\begin{array}{c}\text { No. of } \\
\text { patients }\end{array}$ & $\begin{array}{c}\text { 5-year cancer-specific } \\
\text { survival (\%) }\end{array}$ & p-value \\
\hline 2 & 42 & 71.4 & 0.05 \\
$\geq 3$ & 96 & 55.2 & \\
$2-3$ & 70 & 70.0 & 0.007 \\
$\geq 4$ & 68 & 50.0 & \\
$2-4$ & 89 & 65.2 & 0.03 \\
$\geq 5$ & 49 & 51.0 & 0.02 \\
$2-5$ & 98 & 64.3 & \\
$\geq 6$ & 40 & 50.0 & 0.07 \\
$2-6$ & 107 & 62.6 & \\
$\geq 7$ & 31 & 51.6 & \\
\hline
\end{tabular}

Table 3. Prognostic factors for 5-year cancer-specific survival in univariate analysis.

\begin{tabular}{|c|c|c|c|c|}
\hline $\begin{array}{l}\text { Clinico- } \\
\text { pathological } \\
\text { factor }\end{array}$ & Category & $\begin{array}{l}\text { 5-year } \\
\text { survivor group } \\
(\mathbf{n}=173)\end{array}$ & $\begin{array}{c}\text { Non-survivor } \\
\text { group } \\
(\mathrm{n}=76)\end{array}$ & p-value \\
\hline Age & & $64(30-90)$ & $66.5(44-89)$ & 0.08 \\
\hline \multirow{2}{*}{ Gender } & Male & 95 & 44 & \multirow{2}{*}{0.68} \\
\hline & Female & 78 & 32 & \\
\hline \multirow{2}{*}{ Location } & Proximal & 66 & 26 & \multirow{2}{*}{0.57} \\
\hline & Distal & 107 & 50 & \\
\hline \multirow{2}{*}{ Invasion depth } & $\mathrm{T} 1-\mathrm{T} 3$ & 122 & 33 & \multirow{2}{*}{0.0001} \\
\hline & $\mathrm{T} 4$ & 51 & 43 & \\
\hline \multirow[t]{2}{*}{ Differentiation } & $\begin{array}{l}\text { Well diff. } \\
\text { adenoca. }\end{array}$ & 79 & 27 & \multirow[t]{2}{*}{0.16} \\
\hline & Others & 94 & 49 & \\
\hline \multirow{2}{*}{$\begin{array}{l}\text { Lymphatic } \\
\text { invasion }\end{array}$} & None-mild & 68 & 15 & \multirow[b]{2}{*}{0.003} \\
\hline & $\begin{array}{l}\text { Moderate } \\
\text { severe }\end{array}$ & 173 & 61 & \\
\hline \multirow{2}{*}{$\begin{array}{l}\text { Venous } \\
\text { invasion }\end{array}$} & None - mild & 113 & 30 & \multirow{2}{*}{0.0002} \\
\hline & $\begin{array}{l}\text { Moderate } \\
\text { severe }\end{array}$ & 60 & 46 & \\
\hline $\begin{array}{c}\text { Preoperative } \\
\text { serum CEA } \\
(\mu \mathrm{g} / \mathrm{dl})\end{array}$ & & $\begin{array}{c}3.8 \\
(0.6-1034)\end{array}$ & $\begin{array}{c}6.8 \\
(1.1-44.6)\end{array}$ & 0.09 \\
\hline $\begin{array}{l}\text { No. of dissected } \\
\text { lymph nodes }\end{array}$ & & $\begin{array}{c}19 \\
(3-74)\end{array}$ & $\begin{array}{c}17 \\
(6-108)\end{array}$ & 0.21 \\
\hline $\begin{array}{l}\text { No. of } \\
\text { lymphnode } \\
\text { metastases }\end{array}$ & & $\begin{array}{c}1 \\
(1=17)\end{array}$ & $\begin{array}{c}3 \\
(1-19)\end{array}$ & $<0.0001$ \\
\hline \multirow{2}{*}{$\begin{array}{l}\text { Postoperative } \\
\text { adjuvant } \\
\text { chemotherapy }\end{array}$} & Present & 138 & 56 & \multirow{2}{*}{0.32} \\
\hline & Absent & 35 & 20 & \\
\hline
\end{tabular}


prognostic factors (Table 4).

\subsection{Comparisons between the TNM Classification and the Japanese Classification Systems}

Each of the classification systems is shown in Figure 3. In the Japanese classification, N1 is defined as metastasis in 1 to 3 pericolic/perirectal or intermediate lymph nodes; $\mathrm{N} 2$ is defined as metastasis in 4 to more pericolic/perirectal or intermediate lymph nodes, and N3 is defined as metastasis in the main or lateral lymph nodes. Moreover, N1 is defined as Stage IIIa, and N2 and N3 are defined as Stage IIIb independent of invasion depth. On the other hand, in the TNM classification, N1a is defined as metastasis in one regional lymph node; N1b is defined as metastasis in 2 - 3 regional lymph nodes; N2a is defined as metastasis in $4-6$ regional lymph nodes, and $\mathrm{N} 2 \mathrm{~b}$ is defined as metastasis in 7 or more regional lymph nodes. Moreover, by combining these $\mathrm{N}$ categories with invasion depth, the patients with LNM are further divided into three groups, i.e., IIIA, IIIB and IIIC. Cancer-specific survival in each $\mathrm{N}$ category is shown in Figure $\mathbf{4}$ and survival for each stage classification is presented in Figure 5. With respect to the classifications by $\mathrm{N}$ category, in the Japanese classification, cancer-specific sur-
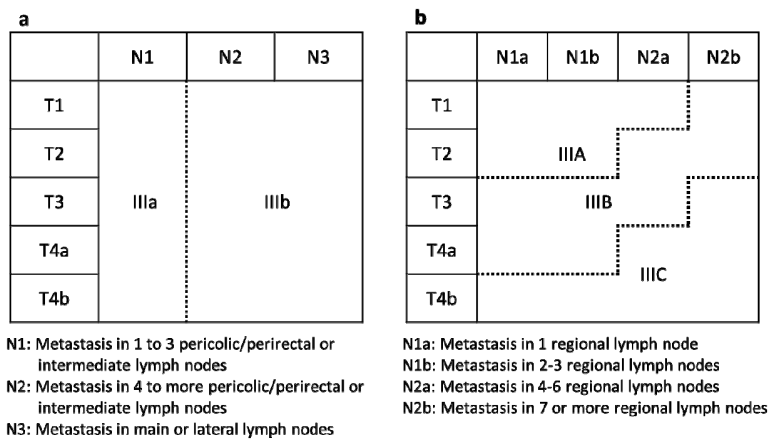

Figure 3. Comparisons between the TNM classification and the Japanese classification systems. (a) Japanese classification of Coloretal Carcinoma. 2nd English Edition; (b) TNM classification of Malignant Tumours, 7th Editon.

Table 4. Prognostic factors for 5-year cancer-specific survival in multivariate analysis.

\begin{tabular}{cccc}
\hline $\begin{array}{c}\text { Clinicopathological } \\
\text { factors }\end{array}$ & p-value & Odds ratio & $\begin{array}{c}\text { 95\% confidence } \\
\text { interval }\end{array}$ \\
\hline Invasion depth (T4) & 0.004 & 2.43 & $1.33-4.43$ \\
$\begin{array}{c}\text { Lymphatic invasion } \\
\text { (moderate - severe) }\end{array}$ & 0.37 & 1.40 & $0.67-2.95$ \\
$\begin{array}{c}\text { Venous invasion } \\
\text { (moderate - severe) }\end{array}$ & 0.04 & 1.98 & $1.03-3.80$ \\
$\begin{array}{c}\text { No. of lymph node } \\
\text { metastases }\end{array}$ & 0.0007 & 1.19 & $1.07-1.31$ \\
\hline
\end{tabular}
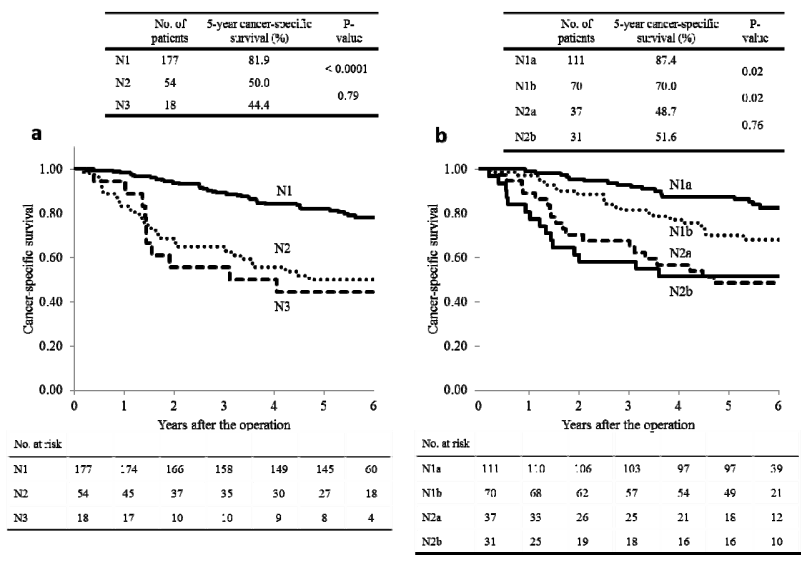

Figure 4. Cancer-specific survival in each $\mathrm{N}$ category. (a) Japanese classification of Coloretal Carcinoma. 2nd English Edition; (b) TNM classification of Malignant Tumours, 7 th Editon.
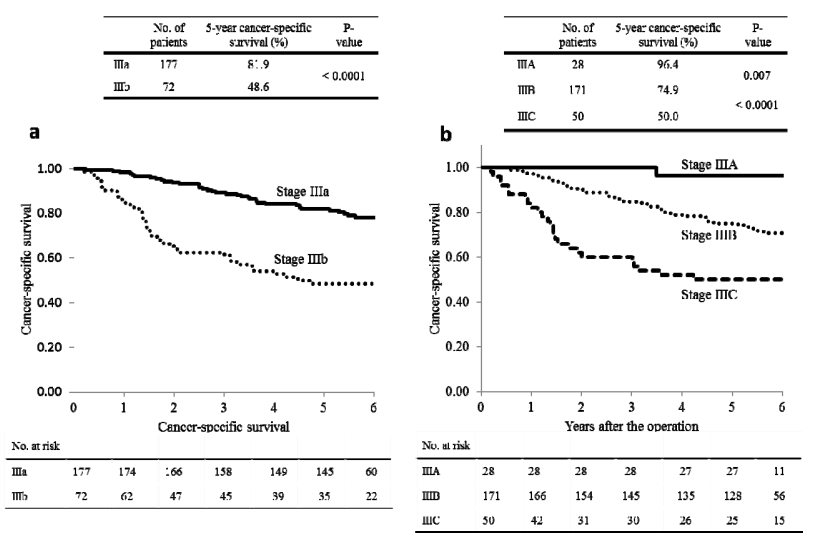

Figure 5. Cancer-specific survival for each stage classification. (a) Japanese classification of Coloretal Carcinoma, 2nd English Edition; (b) TNM classification of Malignant Tumours, 7th Edition.

vival in $\mathrm{N} 1$ was significantly better than that in $\mathrm{N} 2$ or N3 $(p<0.0001)$. However, cancer-specific survival in N2 was nearly equal to that in $\mathrm{N} 3$ and there was no significant difference between $\mathrm{N} 2$ and $\mathrm{N} 3(\mathrm{p}=0.79)$. On the other hand, in the TNM classification, cancer-specific survival in N1a was significantly better than that in N1b $(\mathrm{p}=0.02)$, and that in N1b was significantly better than that in N2a $(p=0.02)$. However, there was no significant difference in cancer-specific survival between N2a and $\mathrm{N} 2 \mathrm{~b}(\mathrm{p}=0.76)$. With regard to stage classification, in the Japanese classification, there was a significant difference in cancer-specific survival between Stages IIIa and IIIb $(\mathrm{p}<0.0001)$. On the other hand, in the TNM classification, cancer-specific survival in Stages IIIA, IIIB and IIIC were stratified into three groups with significant differences (IIIA vs. IIIB; $p=0.007$, IIIB vs. IIIC; $p<$ 0.0001 ). The 5-year cancer-specific survival in Stage IIIA was $96.4 \%$, and was considered to be extremely good. 


\section{DISCUSSION}

LNM is an important determinant of prognosis in patients with colorectal cancer, as acknowledged in both the Japanese and TNM classification systems. In the TNM classification, the $\mathrm{N}$ category is classified by the number of LNM. The validity of the stage classification, which consists of the number of LNM and invasion depth, was confirmed by inspection of a database of more than 100,000 colorectal cancer patients [15]. However, because this inspection was based on surgical outcomes in the United States, it was not clear whether or not the stage classification would be useful in Japan. Moreover, in the Japanese classification, the conventional classification by the distribution of LNM was modified to take into account the number of LNM, in order to integrate with TNM classification. Therefore, we investigated the validity of predicting prognosis based on the number of LNM in node-positive colon cancer.

In this study, cancer-specific survival decreased as the number of LNM increased. There was a tendency toward better rates of cancer-specific survivals among the patients with 1 LNM, compared with those with 2 LNM. This was consistent between classification systems, in that the 1 LNM would be classified into N1a in TNM classification and reflected that the prognoses among the patients with 1 LNM were good. Because the prognoses of the patients with $1 \mathrm{LNM}$ were good, we examined the stratification of cancer-specific survival according to the number of LNM among the patients with 2 or more LNM. Consequently, the stratification of cancer-specific survival between two groups, i.e., the patients with of 2 and $3 \mathrm{LNM}$ and those with 4 or more was the most ideal for stage classification. This result was consistent with the TNM classification, in which the patients with 4 or more LNM were classified into N2. Therefore, it appears to be valid that cancer-specific survival should be stratified into three groups, i.e., the patients with $1 \mathrm{LNM}$, those with 2 and 3 and those with 4 or more. On the other hand, cancer-specific survival among the patients with 7 or more LNM was better than those with 4 or 6 . It would appear that sufficient investigation on the patients with 4 or 5 or 6 LNM was not possible, due to the small number of such patients; this would appear to be a limitation of conducting this type of investigation in a single institution.

Based upon the multivariate analysis, invasion depth (T4), venous invasion and the number of LNM were significant, independent prognostic factors. Some authors have reported that the number of LNM was an independent prognostic factor in multivariate analysis [16-18]. Invasion depth and the number of LNM were also independent prognostic factors in this study. Therefore, this result was consistent in that the stage classifications, i.e., the Japanese classification and the TNM classification, consider invasion depth and the number of LNM.

In comparison of the Japanese and TNM classification systems, the TNM classification appears to be more complicated than the Japanese classification. The reason is because the grades of invasion depth and the number of LNM are subdivided in the TNM classification. Consequently, there are many substages and the intervals between cancer-specific survival in each stage are becoming narrower. Because overlaps and inversions are often recognized in cancer-specific survival, predictions of prognosis that are indicated by each stage are vague [19]. On the other hand, the patients in T1-T2N1 and T1N2a are classified into Stage IIIA in the TNM classification, and the patients in Stage IIIA have a good prognosis $[12,20]$. In other words, these patients with a good prognosis can be distinguished from the patients in Stage III who have a poor prognosis by using the TNM classification. When considering the indication and protocol of postoperative adjuvant chemotherapy in Stage III, it appears necessary to distinguish the patients in Stage IIIA from those in Stage III. In this study, the 5-year cancerspecific survival was $96.4 \%$ and was extremely good. On the other hand, the stage classification by using the number of LNM was introduced in order to integrate with the TNM classification when revising the Japanese classification. However, the concept of distribution of LNM was left in category N3 of the Japanese classification. In other words, metastasis in the main or lateral lymph nodes is defined as N3 regardless of the number of LNM. This is because $\mathrm{N}$ category in the Japanese classification is designed to indicate the extent of lymph node dissection during the operation, as well as predictions of prognosis. Therefore, in this point the Japanese classification is quite distinct from the TNM classification. In this study, there was no significant difference between category $\mathrm{N} 2$ and $\mathrm{N} 3$, and this study was in favor of the TNM classification in which the $\mathrm{N}$ category is classified by the number of LNM. However, there were only eighteen patients in N3 in this study and further research is needed to evaluate this properly. Indeed, Kobayashi et al. [21] reported that the distribution and the number of LNM represented an important index of prognosis in patients with colon cancer. In this study, those data were examined in a single institute, and only a small number of patients were enrolled in this study. Therefore, further investigation using a greater sample population throughout Japan will be necessary.

\section{REFERENCES}

[1] Jemal, A., Siegel, R., Ward, E., Hao, Y., Xu, J. and Thun, M.J. (2009) Cancer statistics, 2009. CA: A Cancer Journal for Clinicians, 59, 225-249. doi:10.3322/caac.20006

[2] Watanabe, T., Itabashi, M., Shimada, Y., Tanaka, S., Ito, 
Y., Ajioka, Y., Hamaguchi, T., Hyodo, I., Igarashi, M., Ishida, H., Ishiguro, M., Kanemitsu, Y., Kokudo, N., Muro, K., Ochiai, A., Oguchi, M., Ohkura, Y., Saito, Y., Sakai, Y., Ueno, H., Yoshino, T., Fujimori, T., Koinuma, N., Morita, T., Nishimura, G., Sakata, Y., Takahashi, K., Takiuchi, H., Tsuruta, O., Yamaguchi, T., Yoshida, M., Yamaguchi, N., Kotake, K., Sugihara, K. and Japanese Society for Cancer of the Colon and Rectum (2012) Japanese society for cancer of the colon and rectum (JSCCR) guidelines 2010 for the treatment of colorectal cancer. International Journal of Clinical Oncology, 17, 1-29. doi:10.1007/s10147-011-0315-2

[3] Griffin, M.R., Bergstralh, E.J., Coffey, R.J., Beart, R.W. and Melton, L.S. (1987) Predictors of survival after curative resection of carcinoma of the colon and rectum. Cancer, 60, 2318-2324. doi:10.1002/1097-0142(19871101)60:9<2318::AID-CNC $\underline{\text { R2820600934>3.0.CO;2-B }}$

[4] Steinberg, S.M., Barkin, J.S., Kaplan, R.S. and Stablein, D.M. (1986) Prognostic indicators of colon tumors: The Gastrointestinal Tumor Study Group experience. Cancer, 57, 1866-1870. doi:10.1002/1097-0142(19860501)57:9<1866::AID-CNC R2820570928>3.0.CO;2-T

[5] Compton, C.C. (2000) Prognostic factors in colorectal cancer: College of American Pathologists Consensus Statement 1999. Archives of Pathology \& Laboratory Medicine, 124, 979-994.

[6] Wong, S.K., Jalaludin, B.B., Henderson, C.J., Morgan, M.J., Berthelsen, A.S., Issac, M.M. and Kneebone, A. (2008) Direct tumor invasion in colon cancer: Correlation with tumor spread and survival. Diseases of the Colon \& Rectum, 51, 1331-1338. doi:10.1007/s10350-008-9274-8

[7] Lim, S.B., Yu, C.S., Jang, S.J., Kim, T.W., Kim, J.H. and Kim, J.C. (2010) Prognostic significance of lymphovascular invasion in sporadic colorectal cancer. Diseases of the Colon \& Rectum, 53, 377-384. doi:10.1007/DCR.0b013e3181cf8ae5

[8] Dukes, C.E. and Bussey, H.J. (1958) The spread of rectal cancer and its effect on prognosis. British Journal of Cancer, 12, 309-320. doi:10.1038/bjc.1958.37

[9] Gastrointestinal Tumor Study Group (1984) Adjuvant therapy of colon cancer: Results of a prospectively randomized trial. New England Journal of Medicine, 310, 737-743. doi:10.1056/NEJM198403223101201

[10] Chapuis, P.H., Dent, O.F., Bokey, E.L., Newland, R.C. and Sinclair, G. (2004) Adverse histopathologic findings as a guide to patient management after curative resection of node-positive colonic cancer. British Journal of Surgery, 91, 349-354. doi:10.1002/bjs.4389

[11] National Institute of Health Consensus Conference (1990) Adjuvant therapy for patients with colon and rectal cancer. JAMA, 264, 1444-1450.

[12] Moeriel, C.G. (1994) Chemotherapy for colorectal cancer. New England Journal of Medicine, 330, 1136-1142. doi:10.1056/NEJM199404213301608

[13] Sobin, L.H., Gaspodarowicz, M. and Wittekind, C. (2009) TNM classification of malignant tumors. 7th Edition, Wiley-Blackwell, New York, 100-105.

[14] Japanese Society for Cancer of the Colon and Rectum (2009) Japanese Classification of Colorectal Carcinoma. 2nd English Edition, Kanehara \& Co. Ltd., Tokyo, 7-10.

[15] Gunderson, L.L., Jessup, J.M., Sargent, D.J., Greene, F.L. and Stewart, A.K. (2010) Revised TN categorization for colon cancer based on national survival outcomes data. Journal of Clinical Oncology, 28, 264-271. doi:10.1200/JCO.2009.24.0952

[16] Cohen, A.M., Tremiterra, S., Candela, F., Thaler, H.T. and Sigurdson, E.R. (1991) Prognosis of node-positive colon cancer. Cancer, 67, 1859-1861. doi:10.1002/1097-0142(19910401)67:7<1859::AID-CNC R2820670707>3.0.CO;2-A

[17] Wang, W.S., Chen, P.M., Chiou, T.J., Liu, J.H., Fan, F.S., Lin, T.C., Jiang, J.K., Yang, S.H., Yen, C.C., Wang, H.S. and Lin, J.K. (2000) Factors predictive of survival in patients with node-positive colorectal cancer in Taiwan. Hepatogastroenterology, 47, 1590-1594.

[18] Vaccaro, C.A., Bonadeo, F.A., Benati, M.L., Quintana, G.M., Rubinstein, F., Mullen, E., Telenta, M. and Lastiri, J.M. (2004) Colorectal cancer staging: Reappraisal of N/ PN classification. Diseases of the Colon \& Rectum, 47, 66-69. doi:10.1007/s10350-003-0004-y

[19] Mori, T. (2010) A comparison of the new (planned) TNM classification and Japanese general rule for staging colorectal cancer. Cancer Investigation, 28, 387-392.

[20] Gunderson, L.L., Jessup, J.M., Sargent, D.J., Greene, F.L. and Stewart, A. (2010) Revised tumor and node categorization for rectal cancer based on surveillance, epidemiology, and end results and rectal pooled analysis outcomes. Journal of Clinical Oncology, 28, 256-263. doi:10.1200/JCO.2009.23.9194

[21] Kobayashi, H., Ueno, H., Hashiguchi, Y. and Mochizuki, H. (2006) Distribution of lymph node metastasis is a prognostic index in patients with stage III colon cancer. Surgery, 139, 516-522. doi:10.1016/j.surg.2005.09.004 